\title{
Prevalence of untreated asthma in a population sample of 6000 older adults in Bristol, UK
}

\author{
L Dow, L Fowler, L Phelps, K Waters, D Coggon, A L Kinmonth, S T Holgate
}

Care of the Elderly, Division of Medicine, University of Bristol, Bristol, UK

L Dow

L Fowler

L Phelps

NHS R\&D Support Unit, North Bristol NHS Trust, Bristol, UK

K Waters

MRC Environmental Epidemiology Unit, Community Clinical Sciences, University of Southampton,

Southampton, UK

D Coggon

University Medicine, University of

Southampton

S T Holgate

General Practice and

Primary Care

Research Unit,

University of

Cambridge,

A L Kinmonth

Correspondence to: Dr L Dow, Care of the

Elderly, Frenchay Hospital, Bristol BS16 1LE, UK

Received 20 July 2000

Returned to authors

6 November 2000

26 January 2001

Accepted for publication

26 February 2001
Cambridge, UK

Lindsey.Dow@bristol.ac.uk

Revised version received

\begin{abstract}
Background-A study was undertaken to estimate the prevalence of untreated asthma in older adults.
\end{abstract}

Methods-A cross sectional population based survey of 6000 men and women aged 65 years and over was performed in 21 general practices in north Bristol, south west England. The main outcome measure was untreated asthma as defined by a two stage process comprising a respiratory questionnaire (symptoms suggestive of asthma or doctor diagnosed asthma not receiving respiratory treatment) followed by lung function tests (significant reversibility following bronchodilators or corticosteroids and/or significant within day variability in peak expiratory flow). Results-4792 of the 6000 participants $(80 \%)$ completed the respiratory questionnaire and, of those not receiving respiratory treatment, 55 reported a previous doctor diagnosis of asthma and a further $696 \mathrm{had}$ symptoms suggestive of asthma. Lung function testing in 280 of 501 randomly selected individuals from these groups resulted in 38 being defined as having asthma and an estimated population prevalence for untreated asthma of $2.4 \%(95 \%$ CI $1.6 \%$ to $3.6 \%)$ in men and $1.2 \%(95 \%$ CI $0.7 \%$ to $2.1 \%$ ) in women. Most subjects (84\%) with untreated asthma had moderate or severe disease. Untreated asthma was most common in individuals with doctor diagnosed asthma (21\%) and those with breathlessness or wheeze (13-20\%).

Conclusion-Untreated asthma in the elderly is a common and important problem. Opportunistic use of appropriate lung function tests in older people with a history of doctor diagnosed asthma or wheeze or breathlessness at rest could identify untreated asthmatics who might benefit from treatment.

(Thorax 2001;56:472-476)

Keywords: asthma; elderly; treatment

Table 1 Definition of symptom groups

Group 1: Wheeze or daytime breathlessness at rest at least once per month

Group 2: Wheeze or daytime breathlessness at rest, but less than once per month, plus either nocturnal breathlessness or chest tightness on waking for at least 60 minutes

Group 3: Nocturnal breathlessness, but no wheeze or daytime breathlessness at rest

Group 4: Morning chest tightness for at least 60 minutes, but no wheeze, daytime breathlessness at rest or nocturnal breathlessness

Group 5: Wheeze or daytime breathlessness at rest, but less than once per month, plus any of breathlessness, wheeze or chest tightness in response to any of (a) going from a warm room into cold air, (b) exercise, (c) going into a smoky room, or (d) going into a room where the air is full of dust

Subjects were classified according to symptoms in the past 12 months. Where a person fulfilled the criteria for more than one symptom group, they were assigned to the one that came first in the list.
Underdiagnosis of asthma has been reported in children and young adults ${ }^{12}$ but little is known about the completeness with which the disease is recognised and treated in older subjects. Diagnosis may be more difficult in the elderly because of the high prevalence of other disorders such as left ventricular failure that can have similar symptoms, and because airflow obstruction is often caused by chronic obstructive pulmonary disease that has limited reversibility. However, where asthma is correctly identified, there is now a wide range of treatments available including new orally administered disease modifying drugs such as leukotriene antagonists that may be particularly useful in some older patients who experience difficulty in using inhalers. ${ }^{34}$

To assess the prevalence and severity of untreated asthma in an elderly population, we carried out a community based cross sectional survey in south west England.

\section{Methods}

The study population comprised 27809 men and women aged 65 years and older (men 6585 aged 65-74 years, 5001 aged 75+; women 7630 aged $65-74$ years, 8593 aged $75+$ ) who were registered with 21 general practices in the north Bristol area. The area served by the practices included inner city, semi-rural, and rural districts. From the age-sex registers of the practices we selected a stratified random sample of 6000 individuals comprising approximately equal numbers of men and women aged 65-74 years and 75 years or older.

Each individual was sent a postal questionnaire about respiratory symptoms in the past year, previous medical history, use of medication, smoking habits, and last full time occupation (or, for married women and widows, that of their husbands). ${ }^{56}$ Non-responders were sent a single reminder after 4 weeks.

From the questionnaire we identified those men and women who were not currently receiving treatment for respiratory disorders (where there was doubt about the treatment being used this was checked with the participant). Within this group we then selected for further investigation all of those who reported that at some time they had been diagnosed as having asthma by a doctor, and a random sample of those with no past diagnosis of asthma but with symptoms suggestive of the disease. These symptoms were classified into five mutually exclusive groups (table 1) and sampling fractions were chosen to ensure adequate representation of each group.

Those participants who agreed to further investigation were visited at home by one of two respiratory research nurses (LF or LP) for 
assessment of lung function. Spirometric tests were carried out in the sitting position with a Vitalograph alpha desktop flow sensing spirometer (Vitalograph Ltd, Buckingham, UK) that was calibrated daily. Forced expiratory volume in one second $\left(\mathrm{FEV}_{1}\right)$ and forced vital capacity (FVC) were recorded as the highest measured values, provided the $\mathrm{FEV}_{1}$ was within $100 \mathrm{ml}$ and $5 \%$ of a second reading. Airflow obstruction was defined as an $\mathrm{FEV}_{1} / \mathrm{FVC}$ ratio of $70 \%$ or lower or, if FVC could not be measured satisfactorily, an $\mathrm{FEV}_{1}$ below $70 \%$ of that predicted for the individual's age, height, and sex according to the formula published by the European Respiratory Society. ${ }^{7}$ If spirometry indicated airflow obstruction, it was repeated 15 and 40 minutes after concurrent inhalation of $200 \mu \mathrm{g}$ salbutamol and $40 \mu \mathrm{g}$ ipratropium bromide. Reversibility was defined as an increase in $\mathrm{FEV}_{1}$ of at least $15 \%$ and at least $200 \mathrm{ml}$.

As well as spirometry, all participants were invited to carry out serial peak expiratory flow (PEF) measurements over a period of 2 weeks. For this purpose a Vitalograph peak flow meter was used with a visually enhanced scale especially adapted for the project by the manufacturer after advice from the medical director of the Royal National Institute for the Blind. Three measurements were recorded early in the morning and three in the evening. From each triplet of measurements we selected the highest value, provided that it was within $20 \mathrm{l} /$ min of the second highest reading. ${ }^{8}$ Daily PEF variability was assessed where satisfactory recordings had been made morning and evening on at least 5 days. It was calculated as (PEFmax - PEFmin)/PEFmax and expressed as a percentage. PEF variability was deemed significant if it was $20 \%$ or higher on one or more days.

At the end of the period of peak flow monitoring, participants who had shown airflow obstruction on spirometric testing but no bronchodilator reversibility and no PEF variability were invited to undergo a trial of oral prednisolone $(30 \mathrm{mg} /$ day $)$ for 2 weeks. If participants refused oral prednisolone, inhaled fluticasone $1 \mathrm{mg}$ daily via a volume spacer device was offered as an alternative. Reversibility was considered to be present if repeat spirometric tests showed an increase in $\mathrm{FEV}_{1}$ of at least $15 \%$ and at least $200 \mathrm{ml}$.
Individuals were considered to have asthma if they had significant PEF variability or reversibility following bronchodilators or corticosteroids. Data were analysed with the Statistical Package for Social Sciences (version 9). Prevalence rates of reported use of treatment for airways disease and of untreated asthma were estimated with adjustment for differences in sampling fractions where appropriate. Confidence intervals (CI) for prevalence estimates were based on the normal or Poisson distributions according to whether or not the underlying observed number of cases exceeded 40 . The severity of untreated asthma was based on PEF variability and $\mathrm{FEV}_{1}$ expressed as a percentage of predicted values according to internationally agreed criteria. ${ }^{9}$

Ethical approval for the study was obtained from Frenchay and Southmead local research ethics committees.

\section{Results}

Questionnaires were returned by 4792 (80\%) of the 6000 subjects to whom they were sent. Their ages ranged from 65 to 104 years (median 74 years) and $2433(51 \%)$ were men. Seven hundred and eight $(14.6 \%)$ indicated that they were using bronchodilators, corticosteroids, or sodium cromoglycate for respiratory disease. Of the remaining 4084, 55 reported a doctor's diagnosis of asthma at some time and a further 696 reported symptoms suggestive of asthma. In addition, 1566 had other respiratory symptoms such as cough and phlegm, and 1767 had no respiratory symptoms.

A total of 501 participants were randomly selected for lung function tests, of whom 280 $(56 \%)$ completed spirometric and/or serial PEF measurements. Table 2 shows the distribution of these men and women according to their symptoms and history of diagnosed asthma. The reasons for failure to complete lung function tests were refusal $(n=129)$, illness $(n=34)$, death in the interval after completing the questionnaire $(n=9)$, change of residence or general practice $(n=8)$, and difficulty with the measurement techniques $(n=41)$. Corticosteroid trials were completed by 21 (12 oral and nine inhaled treatment) of 41 eligible individuals. Of the remainder, seven agreed but withdrew before completion because of minor side effects, six refused, and seven had contraindications.

Table 2 Numbers of subjects tested for asthma according to medical history and symptoms

\begin{tabular}{|c|c|c|c|c|c|c|}
\hline \multirow[t]{2}{*}{ Medical history and symptoms } & \multirow[t]{2}{*}{$\begin{array}{l}\text { Responded to } \\
\text { questionnaire }\end{array}$} & \multirow[t]{2}{*}{$\begin{array}{l}\text { Selected for } \\
\text { testing }\end{array}$} & \multirow[t]{2}{*}{$\begin{array}{l}\text { Tested for } \\
\text { asthma }\end{array}$} & \multicolumn{3}{|l|}{ Method of testing } \\
\hline & & & & $\begin{array}{l}\text { Spirometry and } \\
\text { bronchodilators }\end{array}$ & Serial PEF & $\begin{array}{l}\text { Corticosteroid } \\
\text { trial }\end{array}$ \\
\hline \multicolumn{7}{|l|}{ Using bronchodilators, corticosteroids } \\
\hline \multicolumn{7}{|l|}{ Not using medication for asthma } \\
\hline Previous doctor diagnosed asthma & 55 & 55 & 34 & 27 & 27 & 3 \\
\hline Symptom group 1 & 448 & 287 & 154 & 118 & 124 & 12 \\
\hline Symptom group 2 & 36 & 25 & 15 & 13 & 12 & 1 \\
\hline Symptom group 3 & 59 & 35 & 19 & 14 & 16 & 1 \\
\hline Symptom group 4 & 19 & 15 & 9 & 8 & 3 & 0 \\
\hline Symptom group 5 & 134 & 84 & 49 & 42 & 44 & 4 \\
\hline Other respiratory symptoms & 1566 & 0 & 0 & 0 & 0 & 0 \\
\hline No respiratory symptoms & 1767 & 0 & 0 & 0 & 0 & 0 \\
\hline Total & 4792 & 501 & 280 & 222 & 226 & 21 \\
\hline
\end{tabular}


Table 3 Distribution of those tested for asthma according to sex, age and smoking habits

\begin{tabular}{|c|c|c|c|c|c|c|c|c|}
\hline \multirow[t]{2}{*}{ Symptom group } & \multicolumn{2}{|l|}{ Sex } & \multicolumn{2}{|c|}{ Age (years) } & \multicolumn{4}{|c|}{ Smoking habits } \\
\hline & Male & Female & $65-74$ & $\geqslant 75$ & $\begin{array}{l}\text { Never } \\
\text { smoked }\end{array}$ & Ex-smoker & $\begin{array}{l}\text { Current } \\
\text { smoker }\end{array}$ & Missing \\
\hline Previous doctor diagnosed asthma & 17 & 17 & 25 & 9 & 10 & 19 & 5 & - \\
\hline Symptom group 1 & 92 & 62 & 97 & 57 & 42 & 78 & 29 & 5 \\
\hline Symptom group 2 & 12 & 3 & 9 & 6 & 4 & 8 & 3 & - \\
\hline Symptom group 3 & 9 & 10 & 15 & 4 & 8 & 9 & 1 & 1 \\
\hline Symptom group 4 & 5 & 4 & 5 & 4 & 3 & 6 & - & - \\
\hline Symptom group 5 & 31 & 18 & 30 & 19 & 18 & 22 & 8 & 1 \\
\hline Total & 166 & 114 & 181 & 99 & 85 & 142 & 46 & 7 \\
\hline
\end{tabular}

Table 3 shows the distribution of those tested for asthma by sex, age, and smoking habits. The individuals who were tested for asthma included a higher proportion of men (59\%) and were younger (median age 72 ) than the population from which they were selected (50\% men, median age 74 ).

On testing, 38 individuals were found to have asthma according to the pre-specified diagnostic criteria. Of these, 19 had airflow obstruction that was reversible in response to salbutamol and ipratropium bromide, and 24 showed significant diurnal variation in PEF. The corticosteroid trials did not reveal any additional cases of reversible airflow obstruction. On the basis of lung function testing, the asthma was classified as mild persistent in six individuals, moderate persistent in 14, and severe persistent in 18 . Table 4 gives the prevalence and severity of untreated asthma in each of the symptom groups sampled. The largest number of cases $(n=20)$ was found in symptom group 1 (wheeze or daytime breathlessness at rest at least once per month), and this represented $13 \%$ of those tested in this group. The highest prevalence $(21 \%)$ was found among those reporting a previous diagnosis of asthma by a doctor, but who were not currently on treatment, followed by those in symptom groups 1,2 , and $5(13-20 \%)$. None of the individuals in symptom group 3 (nocturnal breathlessness in the absence of wheeze or daytime breathlessness) had evidence of asthma on lung function testing.

To explore the dependence of our findings on the diagnostic criteria we adopted, the number of subjects with untreated asthma was estimated using several alternative definitions for the disorder. With the daily variability in peak flow redefined as (PEFmax-PEFmin)/ 0.5(PEFmax + PEFmin), the number of cases was 42 . If, in addition, reversibility of airflow obstruction with bronchodilators was redefined as an increase in $\mathrm{FEV}_{1}$ amounting to at least $9 \%$ of the subject's predicted $\mathrm{FEV}_{1}$, the number of cases was $41 .^{10} \mathrm{~A}$ larger difference was found if the criteria for accepting PEF readings were extended to include triplets in which the highest value was up to $40 \mathrm{l} / \mathrm{min}$ more than the second highest reading. With the original definitions of variability and reversibility, the number of cases then increased to 63 .

Table 5 shows the estimated prevalence of untreated asthma in the study population by sex, age, social class (based on the last occupation or that of the husband), and smoking habits. For comparison, the estimated prevalence of treatment with respiratory medication (bronchodilators, corticosteroids, or sodium cromoglycate) is also given for the same population groups. Overall, the estimated prevalence of untreated asthma was $1.7 \%$

Table 4 Frequency and severity of untreated asthma by symptom group

\begin{tabular}{|c|c|c|c|c|c|c|c|c|c|}
\hline \multirow[t]{2}{*}{ Symptom group } & \multirow[t]{2}{*}{ No tested } & \multirow[t]{2}{*}{ No $(\%)$} & \multicolumn{3}{|c|}{ Basis for diagnosis of asthma } & \multicolumn{4}{|c|}{ Severity of asthma } \\
\hline & & & $\begin{array}{l}\text { Spirometry and } \\
\text { bronchodilators }\end{array}$ & $\begin{array}{l}\text { Serial } \\
\text { PEF }\end{array}$ & $\begin{array}{l}\text { Corticosteroid } \\
\text { trial }\end{array}$ & Intermittent & $\begin{array}{l}\text { Mild } \\
\text { persistent }\end{array}$ & $\begin{array}{l}\text { Moderate } \\
\text { persistent }\end{array}$ & $\begin{array}{l}\text { Severe } \\
\text { persistent }\end{array}$ \\
\hline $\begin{array}{l}\text { Previous doctor } \\
\text { diagnosed asthma }\end{array}$ & 34 & $7(21)$ & 1 & 6 & 0 & 0 & 2 & 4 & 1 \\
\hline Symptom group 1 & 154 & $20(13)$ & 9 & 14 & 0 & 0 & 3 & 4 & 13 \\
\hline Symptom group 2 & 15 & $3(20)$ & 2 & 1 & 0 & 0 & 1 & 1 & 1 \\
\hline Symptom group 3 & 19 & $0(0)$ & 0 & 0 & 0 & 0 & 0 & 0 & 0 \\
\hline Symptom group 4 & 9 & $1(11)$ & 1 & 0 & 0 & 0 & 0 & 1 & 0 \\
\hline Symptom group 5 & 49 & $7(14)$ & 6 & 3 & 0 & 0 & 0 & 4 & 3 \\
\hline Total & 280 & $38(14)$ & 19 & 24 & 0 & 0 & 6 & 14 & 18 \\
\hline
\end{tabular}

Table 5 Estimated prevalence (\%) with 95\% confidence intervals of use of respiratory medication and of untreated asthma in the study population according to sex, age, social class, and smoking habits

\begin{tabular}{|c|c|c|c|c|}
\hline & \multicolumn{2}{|l|}{ Men } & \multicolumn{2}{|l|}{ Women } \\
\hline & Respiratory medication & Untreated asthma & Respiratory medication & Untreated asthma \\
\hline \multicolumn{5}{|l|}{ Age (years) } \\
\hline $65-74$ & $13.9(11.9$ to 15.9$)$ & $2.6(1.4$ to 4.3$)$ & $13.1(11.2$ to 15.0$)$ & $2.1(1.1$ to 3.6$)$ \\
\hline$\geqslant 75$ & 18.1 (15.9 to 20.4$)$ & $2.3(1.1$ to 4.2$)$ & 14.1 (12.0 to 16.2$)$ & 0.5 (0.0 to 2.6$)$ \\
\hline \multicolumn{5}{|l|}{ Social class } \\
\hline Non-manual & $12.5(10.4$ to 14.6$)$ & $2.3(1.1$ to 4.2$)$ & $11.2(8.9$ to 13.4$)$ & $1.8(0.6$ to 4.2$)$ \\
\hline Manual & $16.6(14.4$ to 18.8$)$ & $2.4(1.2$ to 4.2$)$ & $12.7(10.3$ to 15.2$)$ & $1.3(0.4$ to 3.0$)$ \\
\hline \multicolumn{5}{|l|}{ Smoking habits } \\
\hline Never smoked & $8.7(6.3$ to 11.1$)$ & $1.6(0.3$ to 4.5$)$ & $9.3(7.7$ to 11.0$)$ & $1.1(0.3$ to 2.5$)$ \\
\hline Ex-smoker & $17.4(15.4$ to 19.4$)$ & $2.8(1.6$ to 4.5$)$ & $18.3(15.4$ to 21.2$)$ & $1.1(0.4$ to 2.4$)$ \\
\hline Current smoker & $18.8(14.7$ to 22.8$)$ & $3.4(1.1$ to 8.0$)$ & $23.0(17.6$ to 28.3$)$ & $2.4(0.3$ to 8.6$)$ \\
\hline All people aged $\geqslant 65$ & $15.7(14.2$ to 17.2$)$ & $2.4(1.6$ to 3.6$)$ & $13.6(12.2$ to 15.1$)$ & $1.2(0.7$ to 2.1$)$ \\
\hline
\end{tabular}


(95\% CI $1.2 \%$ to $2.3 \%$ ). It was higher in men $(2.4 \%, 95 \%$ CI $1.6 \%$ to $3.6 \%)$ than in women $(1.2 \%, 95 \%$ CI $0.7 \%$ to $2.1 \%)$, the difference being most marked at older ages. In contrast, estimated rates of treatment with respiratory medication were similar in the two sexes. Untreated asthma was most common in current smokers.

\section{Discussion}

This study found untreated asthma in an estimated $1.7 \%$ of adults aged 65 years or older, and in most cases ( $84 \%)$, according to levels of impaired lung function, the disease was moderate or severe. Participants who reported episodes of wheeze or breathlessness at rest or a history of past asthma were most likely to show objective evidence of active disease. The use of alternative criteria for defining reversibility had little influence on the prevalence rate of untreated asthma. In contrast, resetting our limit for acceptable blow to blow variability of PEF readings from $201 / \mathrm{min}$ to $40 \mathrm{l} / \mathrm{min}$ almost doubled the number of subjects identified as having untreated disease.

The main strengths of this study were the population approach, the high response rate to the initial questionnaire $(80 \%)$, and the relatively high response rate to lung function testing $(56 \%)$, taking into account the older age of the participants. We chose only to investigate individuals reporting symptoms characteristic of asthma, thus excluding those who only reported symptoms such as phlegm or were asymptomatic. Our previous work has shown that older people who only report symptoms such as phlegm or have no respiratory symptoms are unlikely to have objective evidence of airflow limitation or bronchial hyperresponsiveness. ${ }^{11}$

There were limitations to our protocol for lung function testing which may have led to some misclassification of participants. Airflow obstruction was defined using the $\mathrm{FEV}_{1} / \mathrm{FVC}$ ratio with a cut off of $70 \%$ or lower. As the $\mathrm{FEV}_{1} / \mathrm{FVC}$ ratio declines with increasing age, this approach may identify a proportion of healthy elderly subjects without airways disease. ${ }^{12}$ Although this might have increased the apparent frequency of airflow obstruction within our sample, it would not have contributed to the prevalence of untreated asthma as reversibility and significant PEF variability are unlikely to be found in healthy elderly people without airways disease. Also we only carried out bronchodilator reversibility testing on one occasion and did not use high dose bronchodilators. Performing reversibility testing on more than one occasion and use of higher dose bronchodilators can increase the number of subjects found to have reversible airflow obstruction. ${ }^{13}{ }^{14}$ Gannon and colleagues have shown that significant PEF variability will be found more frequently in subjects in whom PEF is measured at least four times daily compared with twice daily as in this study. ${ }^{15}$ This may have resulted in a degree of underestimation of the prevalence of untreated asthma within our sample.
Most other studies in this age group have concentrated on undiagnosed asthma whereas we chose to look at untreated disease. It is unclear why some patients with diagnosed asthma and ongoing disease were not on treatment. Some may have had asthma that remitted and then recurred. Others may have stopped treatment.

Our results agree with those of a recently performed study in Lincolnshire, UK in which undiagnosed asthma was found in $2.2 \%$ of a single practice random sample of 353 patients aged $60-75$ years. ${ }^{16}$ This study had a similar protocol for lung function testing. Individuals who were identified as having newly diagnosed asthma in that study were not considered to have severe disease as measured by pulmonary function and health status assessment. In contrast, in our larger community sample of untreated asthmatics, using a different approach to assess asthma severity, $84 \%$ of our cases had moderate or severe disease. As with other studies that have examined the prevalence of untreated asthma in older people, we found that investigation of many untreated individuals with symptoms suggestive of asthma failed to show airflow limitation on lung function testing. ${ }^{16}{ }^{17}$ The causes of their symptoms are unclear but a proportion may have had cardiac disease or transient symptoms related to infections.

The costs of screening for untreated asthma were not evaluated in our study, but a Dutch investigation has estimated that the identification of new cases of asthma or chronic obstructive pulmonary disease in an adult population subjected to a screening programme cost $\$ 500-1000$ per case. ${ }^{18}$ We found that the prevalence of untreated asthma was higher in men than in women, particularly in the older age group $(75+)$. There is some evidence that, in men and women with similar symptoms suggestive of asthma, men are less likely to receive a label of asthma and more likely to be considered as having smoking related airways disease. ${ }^{19} 20$

Our results should help general practitioners to identify patients who are most likely to benefit from lung function testing. They suggest that, in older adults with a past diagnosis of asthma and/or current wheeze or breathlessness at rest, about $15-20 \%$ may have asthma. Uncontrolled asthma is considered to account for a significant proportion of health care spending on the frequent exacerbations requiring emergency primary or secondary care. ${ }^{21}$ Appropriate treatment and monitoring of asthma should result in health gains. Our results do not suggest that large scale screening for untreated asthma in elderly people is likely to be cost effective. Case finding among those at high risk and therapeutic trials of treatment would seem to be a more efficient approach deserving formal evaluation.

Future research should focus on defining the pattern of risk factors that best predicts untreated asthma, and on understanding the patient, practitioner, health and social factors that may contribute to the phenomenon. 
The authors thank the participants and staff from the North Bristol general practices for the considerable help and support with this research, Dr Sarah Keir for her help in medical assessment prior to corticosteroid trials, and Jason Poole who helped

LD led the development of the idea for the research and research design, participated in data collection, analyses, and writing up of the paper, and is the main guarantor for the study LF and LP participated in the data collection; KW led data coding and analysis; DC participated in the development of the idea for the research, research design, data analysis, and interpretation and writing up of the paper; ALK and STH participated in the development of the idea for the research, the sampling strategy, interpretation of results, and writing up of the paper.

Funding: The Wellcome Trust provided the grant for this study and GlaxoWellcome provided the drugs and volume space devices used in reversibility testing.

Conflicts of interest: LD, LF, LP have received educational grants from $3 \mathrm{M}$, MSD, Boehringer Ingelheim, and GlaxoWellcome supporting travel, accommodation, and lecture fees for come supporting travel, accommodation, and lecture fees for STH har me STH has received grants to support primary and applied Plough, Novartis, SKB, MSD, GlaxoWellcome, and Yamanouchi.

1 Siersted HC, Boldsen J, Hansen HJ, et al. A population Siersted $\mathrm{HC}$, Boldsen $\mathrm{J}$, Hansen $\mathrm{HJ}$, et al. A population based study of risk factors for underdiagnosis of asthma in

2 De Marco R, Cerveri I, Bugiani M, et al. An undetected burden of asthma in Italy. The relationship between clinical and epidemiological diagnosis of asthma. Eur Respir $\mathcal{F}$ 1998;11:599-60

3 Spector SL, Smith LJ, Glass M. Effects of six weeks of therapy with oral doses of ICI 204219 , a leukotriene D4 receptor antagonist, in subjects with bronchial asthma. $A m$ fRespir Crit Care Med 1994;150:618-23.

4 Allen SC, Prior A. What determines whether an elderly patient can use a metered dose inhaler correctly? $\mathrm{Br} \mathcal{F} \mathrm{D} i$ Chest 1986;80:45-9.

5 Dow L, Coggon D, Osmond C, et al. A population survey of respiratory symptoms in the elderly. Eur Respir 7 1991;4: 267-72.

6 Burney PG, Laitinen LA, Perdrizet S, et al. Validity and repeatability of the IUATLD bronchial symptoms questionnaire:
7 Quanjer PH, Tammeling GJ, Cotes JE, et al. Lung volumes and forced ventilatory flows. Official statement of the European Respiratory Society. Eur Respir 7 1993;6(Suppl 16):5-40.

8 Britton J. Measurement of peak expiratory flow variability in community populations:methodology. Eur Respir f 1997; 10(Suppl 24):42-4s.

9 Global Initiative for Asthma. Global strategy for asthma management and prevention. NHLBI/WHO Workshop Report. NIH National Heart, Lung and Blood Institutes, 1995.

10 Dales RE, Spitzer WO, Tousignant P, et al. Clinical interpretation of airway response to a bronchodilator: interpretation of airway response to a bronchodilator: 138:317-20.

11 Dow L, Coggon D, Holgate ST. Respiratory symptoms as predictors of airways lability in an elderly population. Respir Med 1992;86:27-32.

12 Enright PL, Kronmal RA, Higgins M, et al. Spirometry refrence values for women and men 65 to 85 years of age. $A m$ Rev Respir Dis 1993;147:125-33.

13 Tinkelman DG, Avner SE, Cooper DM. Assessing bronchodilator responsiveness. $\mathcal{f}$ Allergy Clin Immunol 1977;59: 109-14

14 Britton J, Hanley SP, Garrett HV, et al. Dose related effects of salbutamol and ipratropium bromide on airway calibre and reactivity in subjects with asthma. Thorax 1988;43: 300-5.

15 Gannon PFG, Newton DT, Pantin CFA, et al Effect of the number of peak expiratory flow readings per day on the estimation of diurnal variation. Thorax 1998;53:790-2.

16 Dickinson JA, Meaker M, Searle M, et al. Screening older patients for obstructive airways disease in a semi-rural practice. Thorax 1999;54:501-5.

17 Thiadens HA, de Bock GH, Dekker FW, et al. Identifyimg asthma and chronic obstructive pulmonary disease in patients with persistent cough presenting to general patients with persistent cough presenting to general
practioners: descriptive study. $B M F 1998 ; 316: 1286-90$.

18 Van den Boom, van Schayck CP, Rutten-van Molken PMH et al. Active detection of chronic obstructive pulmonary disease and asthma in the general population. Am $\mathcal{F}$ Respir Crit Care Med 1998;158:1730-8.

19 Burrows B, Barbee RA, Cline MG, et al. Characteristics of asthma among elderly adults in a sample of the general population. Chest 1991;100:935-42.

20 Dodge R, Cline MG, Burrows B. Comparisons of asthma, emphysema and chronic bronchitis diagnoses in a general population sample. Am Rev Respir Dis 1986;133:981-6.

21 Barnes PJ, Jonsson B, Klim JB. The costs of asthma. Eur Respir f 1996;9:636-42. 